\title{
Increasing Longevity and the New Demography of Death
}

\author{
George W. Leeson \\ Oxford Institute of Population Ageing and Oxford Martin School, University of Oxford, Oxford OX1 2JD, UK \\ Correspondence should be addressed to George W. Leeson; george.leeson@ageing.ox.ac.uk
}

Received 6 February 2014; Accepted 27 May 2014; Published 24 June 2014

Academic Editor: Sally Guttmacher

Copyright (C) 2014 George W. Leeson. This is an open access article distributed under the Creative Commons Attribution License, which permits unrestricted use, distribution, and reproduction in any medium, provided the original work is properly cited.

\begin{abstract}
The world is ageing at both an individual and population levels and population ageing is truly a global phenomenon, the only notable region of exception being sub-Saharan Africa, which remains relatively young in demographic terms. At an individual level, life expectancies at birth have increased at the global level from 47 years in the mid-20th century to around 70 years today and are expected to rise to 76 years by the mid-21st century. At the population level, the proportion of the world's population aged 60 years and over has increased from 8 percent in the mid-20th century to 12 percent, and by 2050, it is expected to reach 21 percent. In Europe, ageing has continued at a slower rate, but with the emergence of increasing numbers of centenarians. This paper outlines the transition using data from England and Wales from a demography of young death in the mid-19th century to a demography of survival in the 20th century and on to the new demography of old death in the 21st century. The paper provides evidence that it is likely that ages at death will continue to increase, with more and more people reaching extreme old age. At the same time, it is likely that life expectancies at birth will continue to rise, taking life expectancy at birth in England and Wales to 100 years or more by the end of the 21st century. The new 21st century demography of death will lead to annual numbers of deaths far in excess of previous maxima.
\end{abstract}

\section{Introduction}

The world is ageing both at individual and population levels $[1,2]$ and population ageing, which was once regarded as an issue for the developed economies of Europe and North America is truly a global phenomenon now reaching Latin America [3], the only notable region of exception being sub-Saharan Africa, which remains relatively young in demographic terms [4].

At an individual level, life expectancies at birth have increased at the global level from 47.9 years in the mid-20th century to around 70 years today and are expected to rise to 76 years by the mid-21st century. At the population level, the proportion of the world's population aged 60 years and over has increased from 8 percent in the mid-20th century to 11 percent and by 2050 , it is expected to reach 21 percent, equating to more than 2 billion people [4].

In Europe, ageing has continued albeit at a slower rate, but with other elements, namely, supercentenarians and a new demography of death. England and Wales have become demographically mature [5] with more people in mid-2011 aged 60 years and over (12.2 million) than people aged under 15 years (9.9 million) [6].
The scale of ageing-both at the population and individual levels-across the globe is thus by any measure truly dramatic and must surely be regarded as one of the success stories of humankind as more and more people live long, relatively healthy lives. However, this success does not come without some concerns, perhaps, and challenges, most certainly.

With the success of ageing populations has come a return to a demography of death, albeit in a new form. In the mid19th century, European populations were young and shortlived with high levels of infant mortality. For example, more than half of almost 370,000 deaths in England and Wales in 1850 would have occurred among people aged less than 60 years. By the early 21 st century, these same populations have become old and long-lived and almost 90 percent of the deaths in England and Wales now occur among people aged over 60 years and this ageing of death will continue.

This paper will outline, therefore, the new demography of death that the 21st century is predicted to bring to England and Wales and in doing so it looks at the development in the number of centenarians, and in particular the number of supercentenarians (i.e., persons aged 110 years and over)- 
a result of radical life extension and a dramatic witness to this new demography. What we shall outline in this paper is the transition in England and Wales from a demography of young death in the mid-19th century to a demography of survival in the 20th century and on to the new demography of old death in the 21st century.

\section{Population Ageing}

The populations of most countries around the globe are ageing [1-3] and this in its own right is creating a demography of low fertility and increasing longevity, the drivers of ageing populations (e.g., [7]), which will lead to the new demography of death.

Life expectancies have been increasing quite dramatically since the turn of the 20th century $[8,9]$, but what has been particularly striking is the improvement in survival at older ages $[10,11]$ and there seems to be an increasing body of evidence that lives will continue to be extended for some time to come (e.g., $[2,3,12-19])$ but the subreplacement fertility norm into which many European countries seem to have settled is equally impressive and equally challenging [20].

As pointed out by Oeppen and Vaupel [21], female life expectancy at birth in the longest lived country at any time has increased year on year since 1840 at a rate of approximately 3 months per year-likewise males, albeit at a slower rate.

Experts have been continually sceptical about the potential for ever-increasing life expectancies, moving from a belief in limits to lifespan to a belief in a limit to life expectancy. As early as 1928, this limit was predicted to be 64.75 years for both males and females [22]. That forecast at the time of writing had-unbeknown to Dublin-already been surpassed in New Zealand. Later, Olshansky et al. [23] put the limit at 35 years at age 50, but again this was exceeded just 6 years later by Japanese females.

In the following, to introduce the development of the demography of death to the present, we shall outline the drivers of population ageing, namely, declining mortality and declining fertility, before moving to the changing age structures arising from this development and the new demography of death that will develop in the 21st century, employing data from England and Wales.

\section{The Development of Mortality in England and Wales}

3.1. The Number of Deaths and Infant Mortality. The first driver we shall consider is that of mortality and Figure 1 illustrates the development in the total number of deaths (and births) and Figure 2 illustrates the development in the infant mortality rate in England and Wales in the 19th and 20 th centuries. Of course, the absolute number of deaths as a demographic measure is not a helpful measure, but in this context we are considering mortality in simple absolute terms to reveal the changing composition of the demography of death behind the story of improving survivorship which is a part of population ageing.

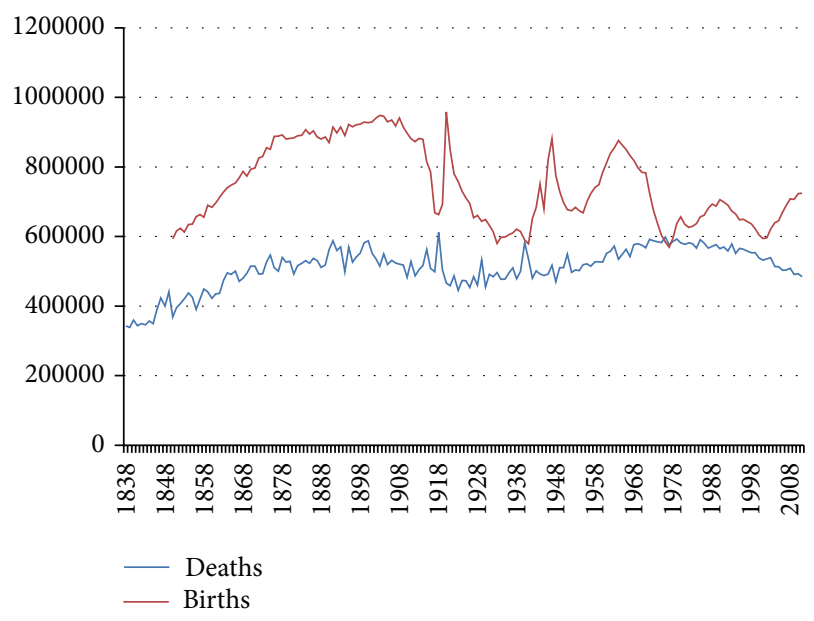

FIgURE 1: The annual number of deaths and births in England and Wales, 1838-2011. Source: data provided by ONS.

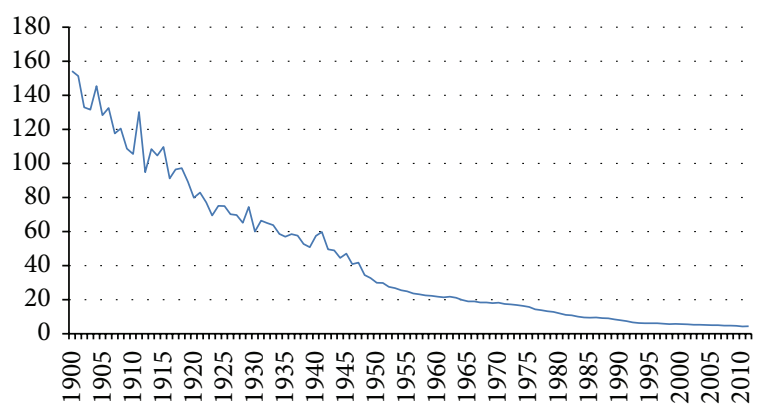

FIGURE 2: Infant mortality rate (deaths under 1 year per 1000 live births) in England and Wales, 1900-2011. Source: data provided by ONS.

In the middle of the 19th century, the absolute number of deaths per year in England and Wales (i.e., deaths registered as occurring in England and Wales) was increasing from around 350,000 to around 600,000 by the end of the 19th century. The number peaked in 1918 at just over 610,000, after which deaths in absolute terms declined to around 440,000 , increasing then as the ageing of the population gained momentum.

By 2011, the number of deaths in the population was just over 484,000 corresponding to a crude death rate of 8.8 per 1000 population-the lowest level recorded for England and Wales [24].

An element of the dramatic changes in the structural development of death and the demography of death was the decline in infant mortality in England and Wales throughout the 20th century (Figure 2). At the turn of the 20th century, infant mortality had been as high as 154 deaths under 1 year per 1000 live births, which corresponded to the infant mortality rate in India in the late 1950s [4]. This rate has been halving every 25 years roughly except for the period from 1975 to 1990 , where the halving time decreased to around 15 years, returning thereafter to be on track for 25 years halving again, 


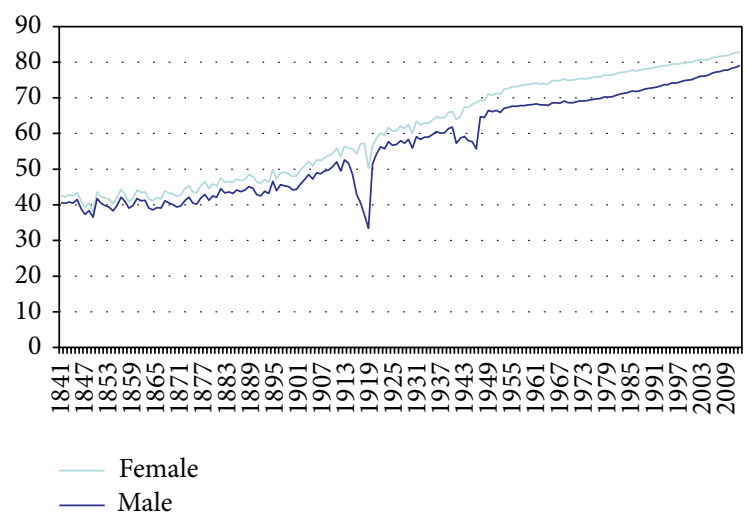

FIGURE 3: Life expectancy at birth for males and females in England and Wales, 1841-2010. Source: data from the Human Mortality database.

ending at just 4.4 deaths under 1 year per 1000 live births in 2011.

3.2. Life Expectancies at Birth. Life expectancies in England and Wales increased equally dramatically in this same period as it appears from Figure 3 (life expectancies at birth) and from Figure 4 (life expectancy at age 65 years). It was not until the early years of the 20th century that life expectancies at birth for both males and females in England and Wales exceeded 50 years, having risen only modestly from around 40 years for both males and females in the early 1840s to 51 years for females and 47 for males, who did not exceed 50 years until 1909. Apart from the impact of both World Wars on male life expectancy-with it falling back to as low as 33 years in 1918 and 56 years in 1945-there has been a steady increase in life expectancies at birth up until the present (Figure 3).

The speed of improvement in life expectancy is also worth noting. The time taken for ten-year incremental increases in life expectancy at birth for both males and females since 1841 decreased quite dramatically initially but has since been more prolonged. So, the first 10 -year increase for females took around 60 years and for males almost 70 years; the second took just over 20 years for females and just over 25 years for males; the third increase took around 26 years for females but more than 40 years for males; and while the fourth 10 year increase for females took almost 60 years, it had still not been achieved for males by 2010 . This reflects in part the transition from juvenile to senescent mortality [12], with improvements in life expectancy at birth being more difficult to achieve as improvements in early and midlife mortality have been almost fully attained.

The difference in male and female life expectancies at birth also exhibits an interesting development. Until around the 1870 s, it remained at approximately 2 years after which it increased to approximately 3 years until the early 1900 s at which time increased to 4 years, and it was not until post 2nd World War that the next 1-year increase occurred, then proceeding to a 6-year difference in the 1960s. In the 1990s, however, the life expectancies began to converge; the

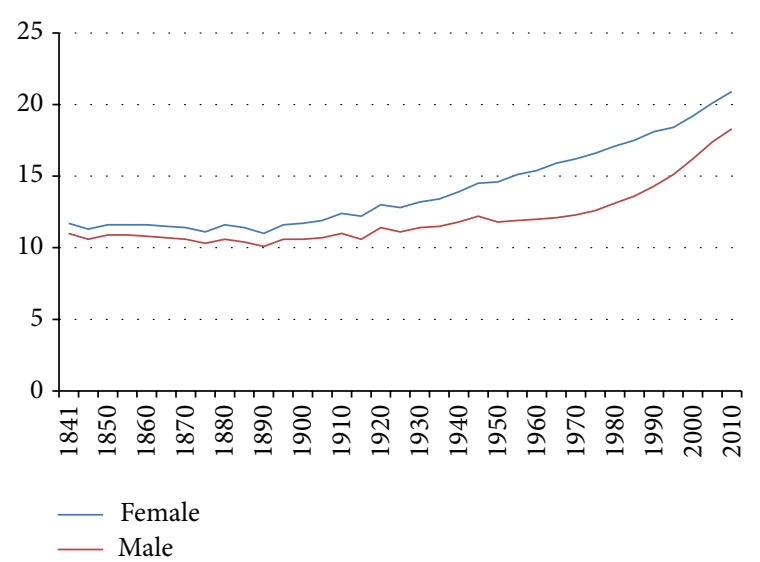

FIGURE 4: Life expectancy at age 65 for males and females in England and Wales, 1841-2010. Source: data from the Human Mortality database.

difference was falling to approximately 5 years in the $1990 \mathrm{~s}$ and to approximately 4 years by the 2010 s.

Thus, the first 50 years of the 20th century saw life expectancies at birth for both males and females increase by 20 years (a 43-percent increase for males and a 42-percent increase for females). In absolute terms, as we shall see later in this paper, it will take 100 years from 1950 to 2050 to increase these life expectancies at birth by an additional 20 years (now only a 29-percent increase for males and a 23-percent increase for females). This is driven by a shift in mortality declines from the younger to the older age groups, reflecting the demographic reversal of the previous conviction that mortality at older ages is intractable $[11,25]$.

3.3. Late-Life Mortality and Life Expectancies at Age 65. Declines in mortality among the extreme aged have been striking [11] with the age-specific mortality rate for females in their 80s and 90s in England and Wales declining from about 180 per 1000 population in 1950 to less than 90 by 1995 . Improvements have also occurred in the second half of the 20th century for males [26-28].

Life expectancy at age 65 in England and Wales was slow in beginning to increase (Figure 4). Indeed, from 1841 to the early 20 th century, it remained more or less the same, and the difference between male and female life expectancies at age 65 at the time was less than 1 year.

The turn of the 20th century saw life expectancy at age 65 begin to increase steadily, particularly for females, and with this came a divergence of male and female life expectancies.

The post 2nd World War era saw the continued increase in life expectancy at age 65 for females, while males began to slow, thereby increasing the male-female difference to around 4 years from the mid-1960s to the mid-1980s. By 2010, males had caught up somewhat and had reduced the difference to approximately 2.5 years. One hundred and seventy years had seen late-life life expectancy increase by just over 7 years for males and almost 9 years for females-something of an achievement given the previous conviction that mortality at older ages was intractable $[11,25]$. 


\section{The Development of Fertility in England and Wales}

The declining levels of mortality and increasing longevity discussed above have been accompanied by fertility declines in line with classical demographic transition theory (e.g., $[29,30])$. We consider this development in the following.

4.1. The Number of Births. As can be seen from Figure 1, the number of live births in England and Wales has experienced a much more pronounced development since the middle of the 19th century, increasing steadily in the third stage of the demographic transition, when mortality is declining but fertility remains high, from around 600,000 per year to almost 950,000 at the beginning of the 20th century.

The 20th century saw a roller-coaster of booms and busts far more pronounced than the "gentle" ups-and-downs of deaths.

The first bust and boom came with war.

There was understandably a dramatic drop in births during the 1st World War which was followed by an equally dramatic but short-lived revival which saw the number of live births increase from around 660,000 in 1918 to more than 950,000 in 1920.

The second bust and boom came with war.

A more or less continual decline follows after 1920 until the early years of the 2nd World War, after which England and Wales experience their first baby-boom in modern times with more than 750,000 live births in 1944 rising again to more than 880,000 in 1947.

After 2nd World War, the cycle of boom and bust has been one of demographic momentum-children of children, so to speak.

So, the next baby-boom, which defined the baby-boom generation in England and Wales, began in 1955, peaked in 1964, and bottomed in 1977. From 1956 to 1976 inclusive, there were fifteen and a quarter million live births in England and Wales, but 1977 with just under 570,000 births saw the lowest number of live births in a single year since 1850 . The children of the baby-boomers provided another more modest baby boom in the 1980s, but live births busted again in 2001 (less than 600,000$)$, a quarter of a century after the previous bust in 1977.

4.2. Total Fertility. In considering the development from the end of the classical demographic transition and into the second demographic transition, it should be remembered that in the mid-18th century total fertility in England and Wales was at around 3.75-4.5, from where it rose to around 5.75 in the early 1800 s [31].

The 20th century then saw fertility in England and Wales fall towards replacement level in the continued fertility decline of the demographic transition and then as illustrated in Figure 5 to below replacement in the second demographic transition [32], leaving England and Wales still in a low fertility cycle after almost 40 years of below replacement fertility. Figure 5 reveals the low fertility plateau of the period

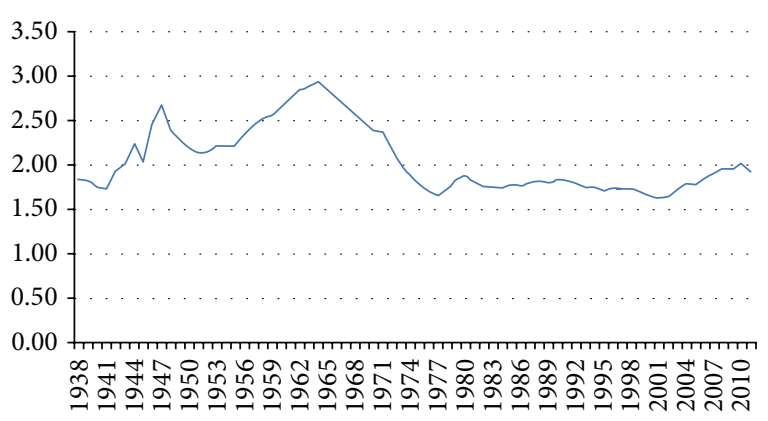

Figure 5: Total fertility in England and Wales, 1938-2011. Source: data provided by ONS.

1973-2011 which is causing concern among demographers and policy makers [33].

\section{The New Demography of Death}

5.1. Life Expectancy in the 21st Century. It is predominantly the combination of the development in fertility and mortality outlined above that brings about the ageing of the population and the transformation of the population pyramid, although of course international migration also plays a role.

In England and Wales, the 20th century saw a transformation of the classic population pyramid as the outlined changes in fertility, early life and then later life mortality passed into and through the age profile of the population.

The societies of the future with highly mature populations will be faced with a multitude of challenges arising from these demographic developments, but of course societies will also change-and will need to change in response to this maturing demography. Population ageing is often equated with an increasing number and proportion of frail, dependent older people who become an increasing burden on society and family. The numbers themselves are a warning that societies need to change with the changing demography.

One consequence of the numbers change is the new demography of death.

Mortality at advanced ages is being delayed and although the future remains difficult to predict, there does seem to be an increasing body of evidence that around the world lives will continue to be extended for some time to come (e.g., [2, $3,12-19,21])$.

Figure 6 illustrates the predicted development in life expectancy at birth and at age 65 years for males and females, respectively, in England and Wales from 2010 to 2100. By the turn of the next century, life expectancies at birth are predicted to be 93 years for males and 95.6 years for females in England and Wales, while at age 65 years, life expectancies are expected to be 29.9 years for males and 31.1 years for females.

5.2. Extreme Longevity for More People. According to data provided by the Office for National Statistics and the Human Mortality Database, the number of people aged 100 years and over in England and Wales increased from less than 200 in 1922 to 570 in 1961. By 1981, this number had climbed to 


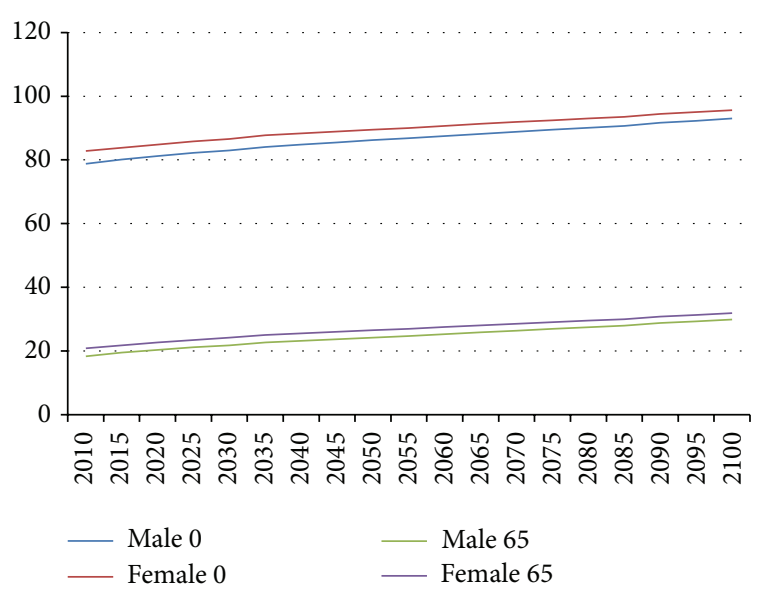

FIGURE 6: Life expectancies at birth and at age 65 years for males and females, respectively, in England and Wales from 2010 to 2100. Source: Office for National Statistics.

2,418 and to 12,318 in 2012 and by the middle of the century the number is expected to be close to 300,000 [34]. Own calculations suggest that the figure will be around 1 million by 2100. It is estimated that around a third of babies born in England and Wales in 2012 will survive to celebrate their 100th birthday and between 5 and 15 percent of males and between 9 and 20 percent of females aged 65 years in 2012 can expect to reach 100 years of age. (These ranges refer to the differences between the low life expectancy variant, principal projection, and high life expectancy variant). (Office for National Statistics (2012b) [35]).

So more people are living longer and the longest lived are living longer too. The survival curve will continue to become more and more rectangular in shape-and it may also be stretched along the age axis as a result of extending maximum lifespan. This is supported by estimates from the Office of National Statistics for England and Wales [13, 14]. From the 1960s to the late 1990s in England and Wales, the highest verified age at death has ranged from 109 to 115 years. If future death rates fall in line with official projections, the highest ages being reached in the 2080s will be 116 to 123 years, and these will be from the baby-boom cohort of around 1966 [13].

5.3. More Deaths. As we have outlined, in the middle of the 19th century, the absolute number of deaths per year in England and Wales was increasing from around 350,000 to around 600,000 by the end of the 19th century. The number peaked in 1918 at just over 610,000, after which deaths in absolute terms declined to around 440,000 , increasing then as the ageing of the population gained momentum.

By 2011, the number of deaths in the population was just over 484,000 corresponding to a CDR of 8.8 per 1000 population - the lowest recorded for England and Wales [24].

What of the future?

The combination of the population dynamics discussed translates into a new demography of death. Let us extend the data on deaths in England and Wales in Figure 1 to cover the 21st century (Figure 7).

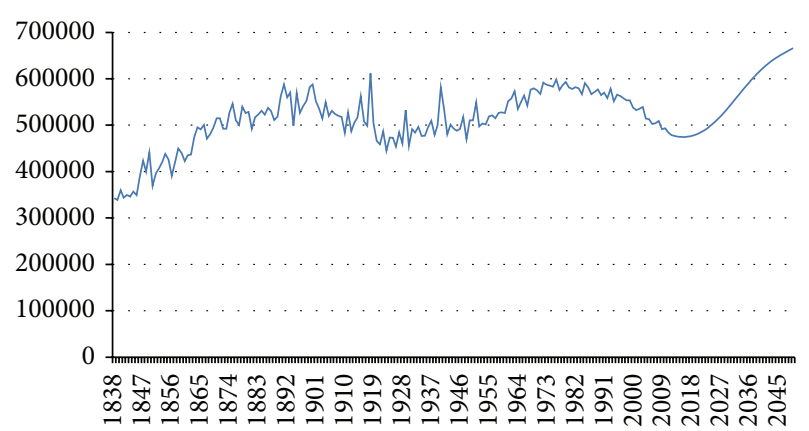

FIgURE 7: The annual number of deaths and births in England and Wales, 1838-2050. Source: data provided by Office for National Statistics.

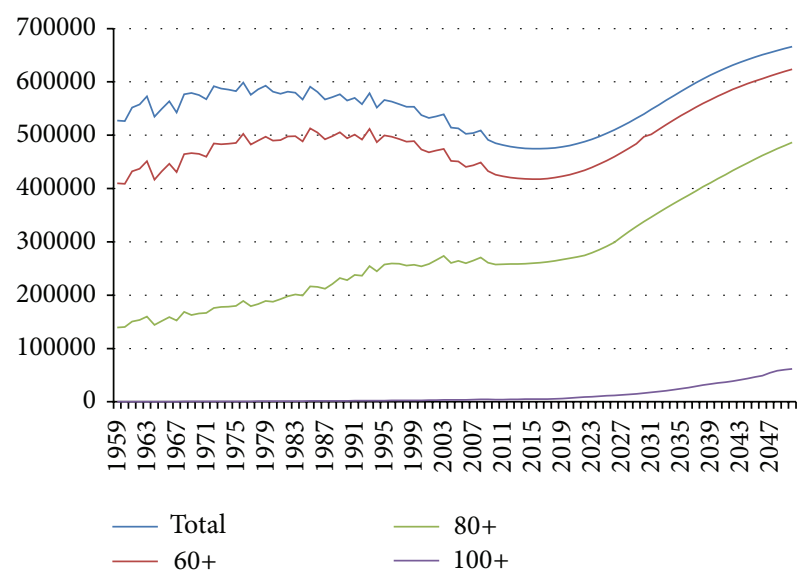

FIGURE 8: The annual number of deaths in England and Wales, 19592050. Total, aged 60+, 80+, and 100+ years, respectively. Source: own calculations from data provided by Office for National Statistics.

The development of this demography of death over the 200 year period from the mid-19th to the mid-21st century is striking. The total number of deaths in England and Wales increases from 342,760 in 1838 , when 50 percent of a cohort was dead by age 45 years, to almost twice that number, 666,253 in 2050, when 50 percent of a cohort will be surviving to age 90 years. The latter part of the 20th century witnessed deaths on an absolute scale per annum comparable to the years of the 1st World War, and by 2050, levels will be higher than ever previously experienced.

But it is the structure of this new demography of death that is interesting (Figure 8).

Since 1959, death has been dominated by deaths of people aged 60 years and over and this domination has increased and will continue to increase at least until the middle of this century. In 1959, 78 percent of deaths were people aged 60 years and over. This had increased to 88 percent by 2009 and is predicted to reach 94 percent by 2050. And in line with the ageing of the population of England and Wales, the proportion of the 60-plus deaths aged 80 years and over has also increased and continues to increase-from 34 percent in 1959 to 60 percent in 2009 and 78 percent in 2050. 
All of this reflects the continuing rectangularisation of the survival curve [8].

\section{Concluding Remarks}

This paper has outlined the new demography of death that the 21st century is predicted to bring, by way of example to England and Wales, and has looked at the development in the number of centenarians and supercentenarians-a result of radical life extension and a dramatic witness to this new demography. The paper has outlined the transition using data from England and Wales from a demography of young death in the mid-19th century to a demography of survival in the 20 th century and on to the new demography of old death in the 21 st century.

The paper provides evidence that it is likely that ages at death will continue to increase, with more and more people reaching extreme old age. At the same time, it is likely that life expectancies at birth will continue to rise, taking life expectancy at birth in England and Wales to 100 years or more by the end of the 21st century.

The new 21st century demography of death will lead to annual numbers of deaths far in excess of previous maxima.

While this is in all respects a natural consequence of the ongoing demographic development in England and Wales and similar developed economies, there remains the question: are we prepared for this new demography death, its scale and structure, as individuals, families, communities, and societies?

The ageing of European populations in the latter part of the 20th century was a demographic surprise brought about by a combination of demographic resistance to dismissing the idea of a limit to human longevity and the creeping decline in mid- and late-life mortality as the prevention and treatment of for example, heart disease improved. Experience proved we had pushed old age into our $80 \mathrm{~s}$.

The future could be an equal demographic surprise if we ignore the evidence of the new demography of death, which also would suggest that the lives of more and more people will continue to be extended and centenarians and supercentenarians would comprise an increasing number and proportion of our populations.

While this paper has developed economies as its point of departure-with data from England and Wales specificallythe new demography of death is also a 21st century challenge for the emerging economies of the world, where life expectancies continue to increase. However, these economies are challenged additionally by the speed of their fertility transitions, which in many instances are occurring in one or at most two generations.

So regardless of where we live, this all has fundamental consequences for the way in which we as individuals view our extending lives, but also for the way in which our lives are compartmentalised into an early-life phase of education, a midlife phase of work, and a late-life phase of retirement.

How could/should we begin to prepare ourselves for this new demography of death? At the individual level, it presents a challenge to our life course planning, which needs to address this compartmentalisation mentality. It is also a challenge to our concepts of old age and retirement (is retirement even at age 75 years sustainable?). Family dynamics will be challenged by the survival of extreme aged generations delaying intergenerational succession and depending on smaller families for support in frail and dependent old age.

The prospect of declining population size as well as this new demography of death raises even more and different issues as the workforce contracts. This would lead to policy discussions about controlled labour immigration, perhaps, to compensate for the declining local workforce.

Buried in this demography of death is, however, a success story of survival. Let us not be dismayed by that but let us begin to discuss what it means.

\section{Conflict of Interests}

The author declares that there is no conflict of interests regarding the publication of this paper.

\section{References}

[1] G. W. Leeson, "Demography, politics and policy in Europe," in Setting EU Priorities 2009, P. Ludlow, Ed., pp. 102-124, The European Strategy Forum, Ponte de Lima, Portugal, 2009.

[2] G. W. Leeson, "Future prospects for longevity," Post Reproductive Health, vol. 20, no. 1, pp. 11-15, 2014.

[3] G. W. Leeson, "Prepared or not, Latin America faces the challenge of aging," Current History, vol. 110, no. 733, pp. 75-80, 2011.

[4] United Nations, World Population Prospects: 2012 Revision, United Nations, Department of Economic and Social Affairs, New York, NY, USA, 2013.

[5] S. Harper, "Mature societies: planning for our future selves," Daedalus, vol. 135, no. 1, pp. 20-31, 2006.

[6] Office for National Statistics, Annual Mid-Year Population Estimates for England \& Wales, Statistical Bulletin, 2012.

[7] R. Lee, “The demographic transition: three centuries of fundamental change," Journal of Economic Perspectives, vol. 17, no. 4, pp. 167-190, 2003.

[8] J. F. Fries, "Aging, natural death, and the compression of morbidity," The New England Journal of Medicine, vol. 303, no. 3, pp. $130-135,1980$.

[9] G. W. Leeson, "Demographic ageing in Denmark in the twentieth century," The Eugenics Society Bulletin, vol. 14, no. 2, pp. 46-52, 1982.

[10] G. W. Leeson, “The mortality of older people in Denmark, 19601980,” Ugeskrift for Loeger, vol. 143, pp. 2324-2327, 1981.

[11] J. W. Vaupel, "Demographic analysis of aging and longevity," The American Economic Review, vol. 88, no. 2, pp. 242-247, 1998.

[12] J. Bongaarts, "How long will we live?" Population and Development Review, vol. 32, no. 4, pp. 605-628, 2006.

[13] R. Thatcher, "The demography of centenarians in England and Wales," Population Trends, no. 96, pp. 5-12, 1999.

[14] R. Thatcher, "The demography of centenarians in England and Wales," Population, vol. 13, no. 1, pp. 139-156, 2001.

[15] S. J. Olshansky, B. A. Carnes, and A. Desesquelles, "Prospects for human longevity," Science, vol. 291, no. 5508, pp. 1491-1492, 2001. 
[16] J.-M. Robine, Y. Saito, and C. Jagger, "The emergence of extremely old people: the case of Japan," Experimental Gerontology, vol. 38, no. 7, pp. 735-739, 2003.

[17] J. R. Wilmoth and J.-M. Robine, "The world trend in maximum life span," Population and Development Review, vol. 29, pp. 239257, 2003.

[18] K. Christensen, G. Doblhammer, R. Rau, and J. W. Vaupel, "Ageing populations: the challenges ahead," The Lancet, vol. 374, no. 9696, pp. 1196-1208, 2009.

[19] J. W. Vaupel, "Biodemography of human ageing," Nature, vol. 464, no. 7288, pp. 536-542, 2010.

[20] J. Goldstein, W. Lutz, and M. R. Testa, "The emergence of subreplacement family size ideals in Europe," Population Research and Policy Review, vol. 22, no. 5-6, pp. 479-496, 2003.

[21] J. Oeppen and J. W. Vaupel, "Broken limits to life expectancy," Science, vol. 296, no. 5570, pp. 1029-1031, 2002.

[22] L. I. Dublin, Health and Wealth, Harper, New York, NY, USA, 1928.

[23] S. J. Olshansky, B. A. Carnes, and C. Cassel, "In search of Methuselah: estimating the upper limits to human longevity," Science, vol. 250, no. 4981, pp. 634-640, 1990.

[24] Office for National Statistics, Deaths Registered in England and Wales (Series DR), 2011, Statistical Bulletin, Office for National Statistics, London, UK, 2012.

[25] J. R. Wilmoth, "In search of limits: what do demographic trends suggest about the future of human longevity," in Between Zeus and the Salmon, K. W. Wachter and C. E. Finch, Eds., pp. 38-64, National Academy Press, Washington, DC, USA, 1997.

[26] V. Kannisto, Development of Oldest-Old Mortality, 1950-1990, Odense University Press, Odense, Denmark, 1994.

[27] V. Kannisto, The Advancing Frontier of Survival: Life Tables for Old Age, Odense University Press, Odense, Denmark, 1996.

[28] V. Kannisto, J. Lauritsen, A. R. Thatcher, and J. W. Vaupel, "Reductions in mortality at advanced ages: several decades of evidence from 27 countries," Population \& Development Review, vol. 20, no. 4, pp. 793-810, 1994.

[29] D. Kirk, "Demographic transition theory," Population Studies, vol. 50, no. 3, pp. 361-387, 1996.

[30] J. Hobcraft, "Fertility in England and Wales: a fifty-year perspective," Population Studies, vol. 50, no. 3, pp. 485-524, 1996.

[31] R. Woods, The Demographics of Victorian England and Wales, Cambridge University Press, Cambridge, UK, 2000.

[32] D. J. van de Kaa, "Europe's second demographic transition," Population Bulletin, vol. 42, no. 1, pp. 3-57, 1987.

[33] T. Sobotka, "Does persistent low fertility threaten the future of European populations?" in Demographic Challenges for the 21st Century, J. Surkyn, P. Debrosere, and J. van Bavel, Eds., pp. 2790, Brussels University Press, Brussels, Belgium, 2008.

[34] J. Evans, Number of Future Centenarians by Age Group, Department for Work and Pensions, London, UK, 2011.

[35] Office for National Statistics, What Are the Chances of Surviving to Age 100? Office for National Statistics, London, UK, 2012. 

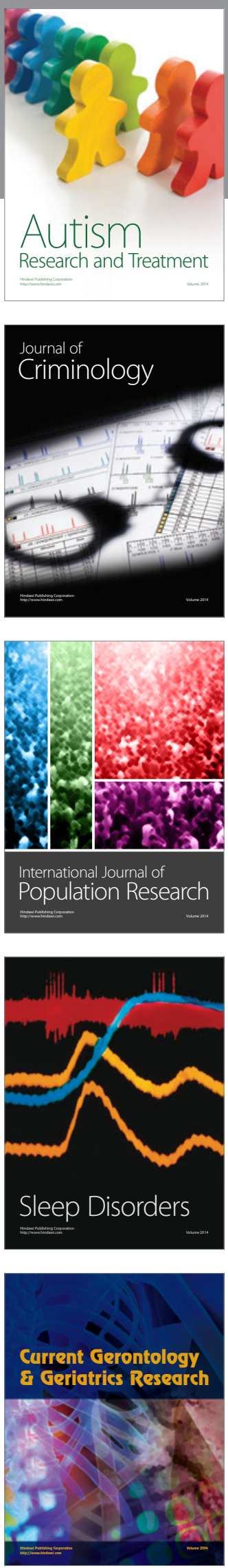
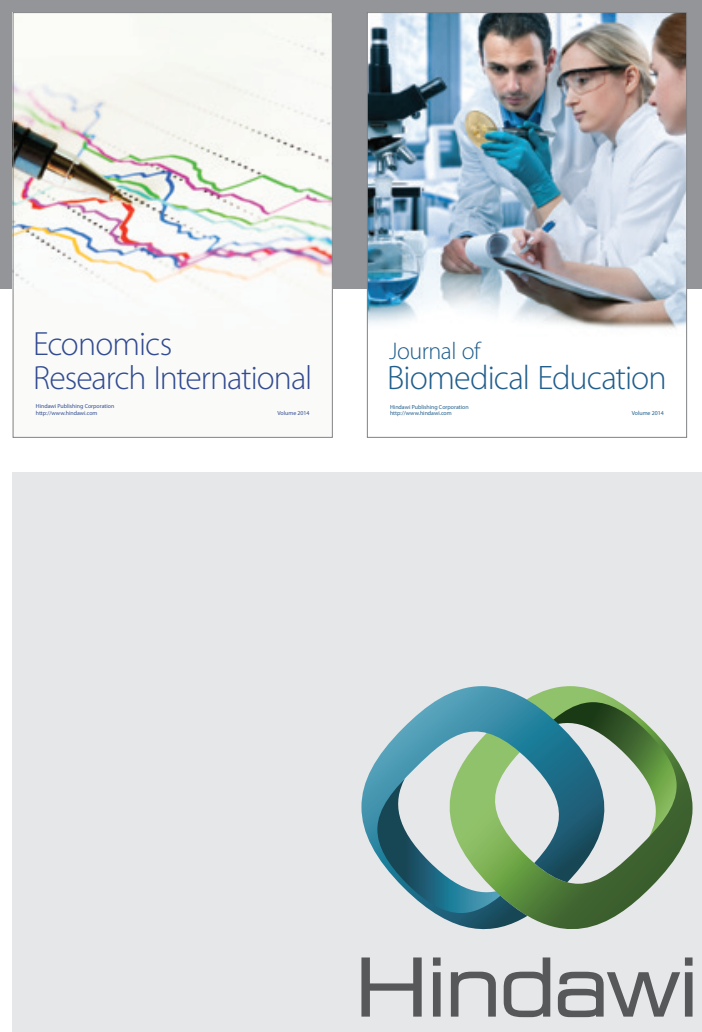

Submit your manuscripts at

http://www.hindawi.com
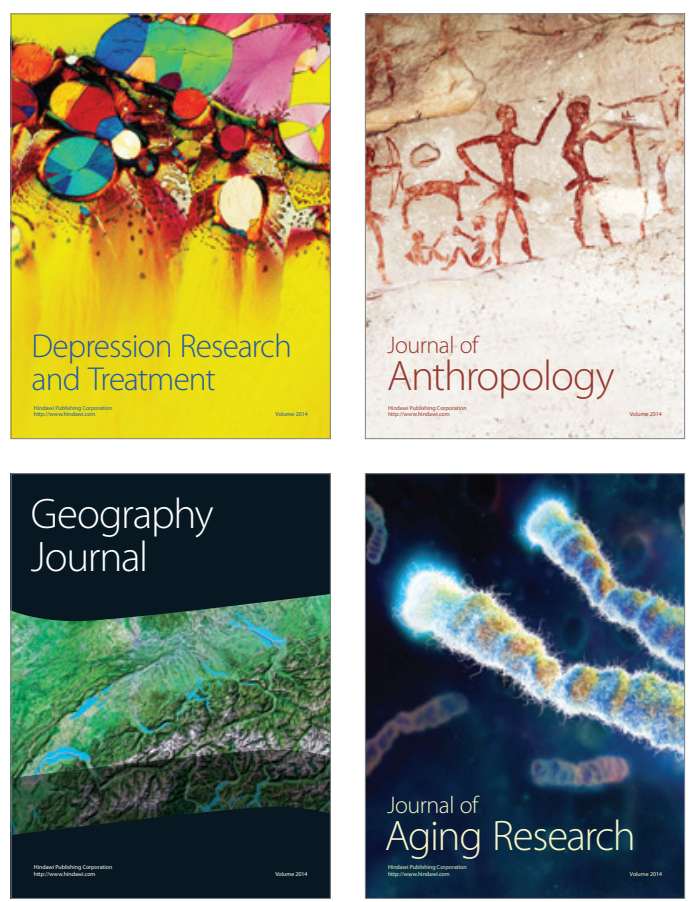
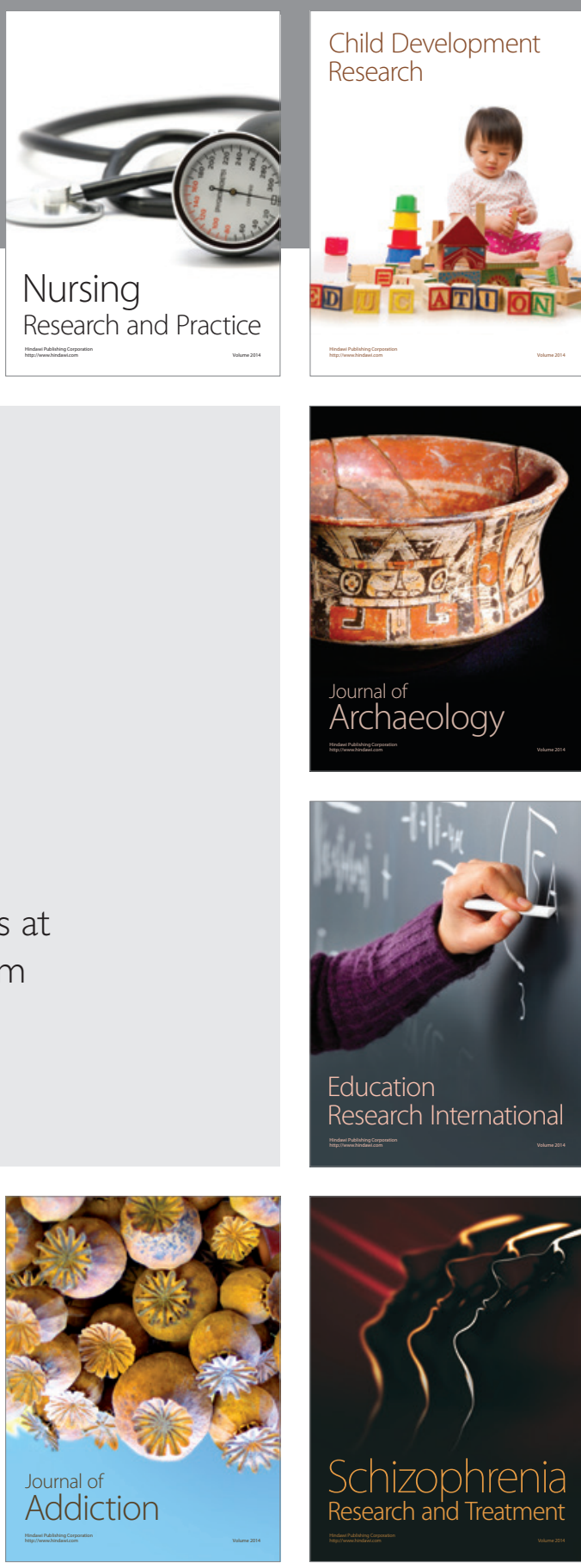

(D)
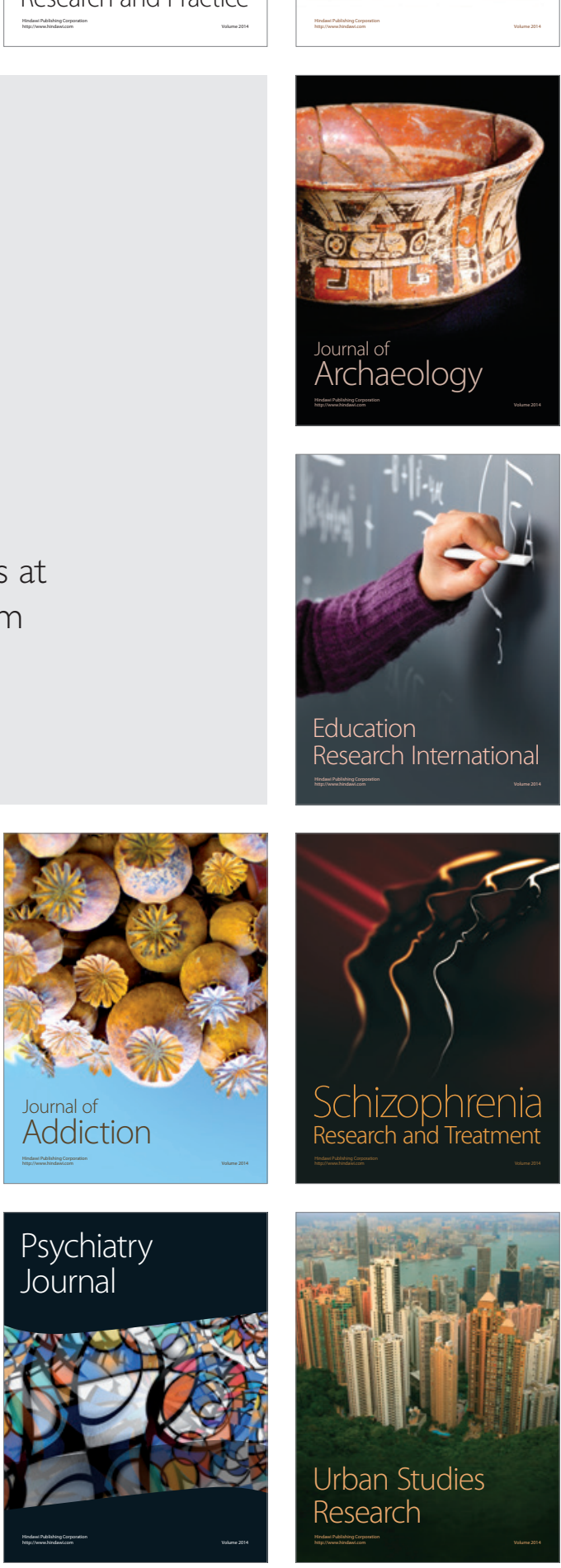